\title{
SMR
}

\section{Serum miR-200c expression level as a prognostic biomarker for gastric cancer}

\author{
H.-P. Zhang ${ }^{1 *}$, F.-B. Sun ${ }^{2 *}$ and S.-J. Li ${ }^{2}$ \\ ${ }^{1}$ Department of Gastrointestinal Surgery, Yantai Yuhuangding Hospital, Yantai, \\ Shandong, China \\ 2Department of Hepatobiliary Surgery, Yantai Yuhuangding Hospital, Yantai, \\ Shandong, China \\ *These authors contributed equally to this study. \\ Corresponding author: S.-J. Li \\ E-mail: yantai_lishaojun@126.com
}

Genet. Mol. Res. 14 (4): 15913-15920 (2015)

Received July 2, 2015

Accepted September 28, 2015

Published December 7, 2015

DOI http://dx.doi.org/10.4238/2015.December.7.2

\begin{abstract}
The aim of the present study was to analyze the serum expression level of microRNA-200c (miR-200c) in gastric cancer (GC) patients and to determine the relationship between this expression and clinicopathological features and survival. Serum samples were obtained from 98 patients with GC between February 2008 and January 2013. Quantitative RT-PCR was used to assess miR-200c expression levels in serum samples. Survival curves were plotted using the Kaplan-Meier method, and differences between survival curves were compared by the log rank test. The Cox proportional hazard regression model was used to analyze the risk factors for GC. Relative serum miR-200c level was found to be significantly higher in patients with GC than healthy controls. Mean serum miR-200c level was $97.43 \pm 26.16$ in the GC group and $20.79 \pm$ 14.61 in the control group $(P<0.0001)$. Serum miR-200c level was also significantly associated with tumor grade $(P=0.01)$ and TNM stage $(P=$ 0.009). Kaplan-Meier survival curves demonstrated that the overall survival rate was significantly lower in the patients with high serum miR-200c level than in those with low levels ( 27.9 vs $55.9 \%, P=0.007)$. In addition,
\end{abstract}


multivariate analysis confirmed that the hazard risk (HR) of death was significantly higher in patients with high serum miR-200c expression levels compared with low expression levels $(\mathrm{HR}=4.01,95 \% \mathrm{Cl}=2.67-10.02, \mathrm{P}$ $=0.006$ ). The relative expression of serum miR-200c in GC patients was significantly higher compared to healthy controls, and it may prove to be useful in assessing the prognosis of GC.

Key words: Serum; miR-200c; Prognostic biomarker; Gastric cancer

\section{INTRODUCTION}

Gastric cancer (GC) is the fourth most common human malignant disease and the second leading cause of cancer-related deaths worldwide (Bertuccio et al., 2009; Ferro et al., 2014). Due to the difficulties of early diagnosis, quantities of patients were diagnosed with GC until in its advanced stage; unfortunately, even after radical surgery and adjuvant therapy, the 5-year overall survival (OS) of GC patients is relatively low (Yang, 2006). Thus, to improve the clinical outcome of GC patients, we need new prognostic biomarkers that can help us identify patients with high risk and undertake a specific therapeutic strategy.

MicroRNAs (miRNAs) are noncoding RNA molecules of approximately 21 to 23 nucleotides in length that regulate target gene expression by interfering with their transcription or by inhibiting translation (Esteller, 2011; Kong et al., 2012; Rutnam et al., 2012). miRNAs play crucial roles in diverse cellular biological processes, including cell differentiation, proliferation, growth, migration, and survival. The discovery that miRNA expression is frequently dysregulated in malignant tumors underpins their critical role, which is a matter of active investigation, both from a basic science perspective and for its clinical usefulness. Circulating biomarkers are a promising means of diagnosis and prognosis, since blood samples are easily obtainable. Related studies have shown that human serum contains miRNAs and that their expression patterns can potentially be used as clinically diagnostic and prognostic biomarkers of various cancers (Cortez et al., 2009, 2012).

MicroRNA-200c (miR-200c) is a member of the miR-200 family, which is overexpressed in several cancers, including ovarian cancer (Iorio et al., 2007; Bendoraite et al., 2010), cervical cancer (Lee et al., 2008), bile duct cancer (Meng et al., 2006), nasopharyngeal carcinoma (Zhang et al., 2010), lung cancer (Liu et al., 2012), colorectal cancer (Zhang et al., 2013; Cristobal et al., 2014), and GC as well (Tang et al., 2013; Song et al., 2014). Valladares-Ayerbes et al. (2012) found that the miR-200c blood expression levels in GC patients were significantly higher than in normal controls $(P=0.018)$ and that it has the potential to be a predictor of progression and survival. However, until now, the serum expression level of miR-200c and its clinical significance in GC in Asians have not been investigated. The present study attempted to determine miR-200c in serum samples from GC patients to see its clinical significance and prognostic value in an Asian population.

\section{MATERIAL AND METHODS}

\section{Patients and serum samples}

Serum samples were obtained from 98 patients with GC who had been surgically treated in the Department of Gastrointestinal Surgery, Yantai Yuhuangding Hospital between February 
2008 and January 2013. The clinical characteristics of the study participants are listed in Table 1. No patients in this study had received chemotherapy or radiotherapy prior to blood sampling. Tumors were staged according to the seventh edition of the UICC TNM classification system. Venous blood $(5 \mathrm{~mL})$ was collected from each patient prior to surgery. The control group consisted of 100 healthy volunteers who had never received a diagnosis of malignancy. Blood samples were centrifuged at $2500 \mathrm{rpm}$ and $4^{\circ} \mathrm{C}$ for $10 \mathrm{~min}$. Supernatants were recovered and stored at $-80^{\circ} \mathrm{C}$ until further analysis. Follow-up data for all recruited patients were acquired and the survival time was calculated from the date of surgery to the date of death or last follow-up. Written informed consent was obtained from each patient, and study approval was obtained from the Yantai Yuhuangding Hospital ethics review board.

\begin{tabular}{|c|c|c|c|c|}
\hline \multirow[t]{2}{*}{ Clinicopathological factors } & \multirow[t]{2}{*}{$N$} & \multicolumn{2}{|c|}{ Serum miR-200c level } & \multirow[t]{2}{*}{$P$ value } \\
\hline & & $\operatorname{High}(\mathrm{N}=50)$ & Low $(\mathrm{N}=48)$ & \\
\hline \multicolumn{5}{|l|}{ Age (years) } \\
\hline$<60$ & 47 & 22 & 25 & \multirow[t]{2}{*}{0.53} \\
\hline$\geq 60$ & 51 & 28 & 23 & \\
\hline \multicolumn{5}{|l|}{ Gender distribution } \\
\hline Female & 45 & 23 & 22 & \multirow[t]{2}{*}{0.66} \\
\hline Male & 53 & 27 & 26 & \\
\hline \multicolumn{5}{|l|}{ Histological type } \\
\hline Intestinal & 46 & 15 & 31 & \multirow{3}{*}{0.11} \\
\hline Diffuse & 41 & 29 & 12 & \\
\hline Mixed & 11 & 6 & 5 & \\
\hline \multicolumn{5}{|l|}{ Tumor size } \\
\hline$<5 \mathrm{~cm}$ & 50 & 22 & 28 & \multirow[t]{2}{*}{0.09} \\
\hline$\geq 5 \mathrm{~cm}$ & 48 & 28 & 20 & \\
\hline \multicolumn{5}{|l|}{ Grade } \\
\hline Low & 46 & 17 & 29 & \multirow[t]{2}{*}{0.01} \\
\hline High & 52 & 33 & 19 & \\
\hline \multicolumn{5}{|l|}{ Lymph node metastasis } \\
\hline Yes & 67 & 36 & 31 & \multirow[t]{2}{*}{0.06} \\
\hline No & 31 & 14 & 17 & \\
\hline \multicolumn{5}{|l|}{ TNM stage } \\
\hline $\mathrm{I} / \mathrm{I}$ & 34 & 9 & 25 & \multirow[t]{2}{*}{0.009} \\
\hline $\mathrm{III/IV}$ & 64 & 41 & 23 & \\
\hline \multicolumn{5}{|l|}{ Surgery type } \\
\hline Radical & 79 & 37 & 42 & \multirow[t]{2}{*}{0.07} \\
\hline Palliative & 19 & 13 & 6 & \\
\hline
\end{tabular}

\section{miRNA quantitation by real-time quantitative reverse transcription-polymerase chain reaction (qRT-PCR)}

Total RNA was extracted from tissues using the miRNeasy Mini kit (Qiagen, Hilden, Germany) following the manufacturer instructions. Total RNA containing small RNA was extracted from $500 \mu \mathrm{L}$ plasma using the TRIzol LS reagent (Invitrogen, Carlsbad, CA, USA) and the miRNeasy Mini kit according to the manufacturer instructions. The final elution volume was 30 $\mu \mathrm{L}$. RNA concentration was measured with a NanoDrop 2000 spectrophotometer (Thermo Fisher Scientific, Wilmington, DE, USA). For miRNA qPCR, reverse transcription was performed using the QuantiMir ${ }^{\mathrm{TM}}$ RT kit (System Biosciences, Mountain View, CA, USA). Complementary DNA (cDNA) served as the template for SYBR-Green real-time PCR using Power SYBR-Green PCR 
Master mix (Applied Biosystems, Foster City, CA, USA). The reactions were performed in triplicate on the iCycler $\mathrm{iQ}^{\mathrm{TM}}$ Multi-Color Real-Time PCR Detection System (Bio-Rad, Hercules, CA, USA) using miRNA-specific primers (Applied Biosystems). The amplification profile was denaturation at $95^{\circ} \mathrm{C}$ for $10 \mathrm{~min}$, followed by 50 cycles of denaturation at $95^{\circ} \mathrm{C}$ for $15 \mathrm{~s}$, annealing at $60^{\circ} \mathrm{C}$ for 30 $\mathrm{s}$, and extension at $72^{\circ} \mathrm{C}$ for $1 \mathrm{~min}$. The comparative cycle threshold $(\mathrm{Ct})$ method was applied to quantify the expression levels of miRNAs. The relative amount of miR-200c to small nuclear U6 RNA (RNU6B) was calculated using the equation $2^{-\Delta C t}$, where $\Delta \mathrm{Ct}=\left(\mathrm{Ct}_{\text {miR-200c }}-\mathrm{Ct}_{\mathrm{RNU6B}}\right)$. The foldchange of the gene expression was calculated using the equation $2^{-\Delta \Delta C t}$.

\section{Statistical analysis}

Differences between groups were examined for statistical significance by the Student $t$-test with Yates' correction, the chi-square test, Fisher exact probability test, or the Mann-Whitney U test. Survival curves were plotted using the Kaplan-Meier method, and differences between survival curves were compared by the log-rank test. The Cox proportional hazard regression model was used to analyze the risk factors for gastric cancer. $\mathrm{P}<0.05$ was considered to be statistically significant. The statistical analyses were performed with the SPSS 18.0 software (SPSS, Inc., Chicago, IL, USA).

\section{RESULTS}

\section{Serum level of miR-200c in patients with GC and healthy controls}

Relative serum miR-200c level was found to be significantly higher in patients with GC than healthy controls. Mean serum miR-200c level was $97.43 \pm 26.16$ in the GC group and 20.79 \pm 14.61 in the control group $(P<0.0001$; Figure 1). We divided the $98 \mathrm{GC}$ patients into a high expression group $(\mathrm{N}=50)$ and a low expression group $(\mathrm{N}=48)$, according to the median expression level of miR-200c.

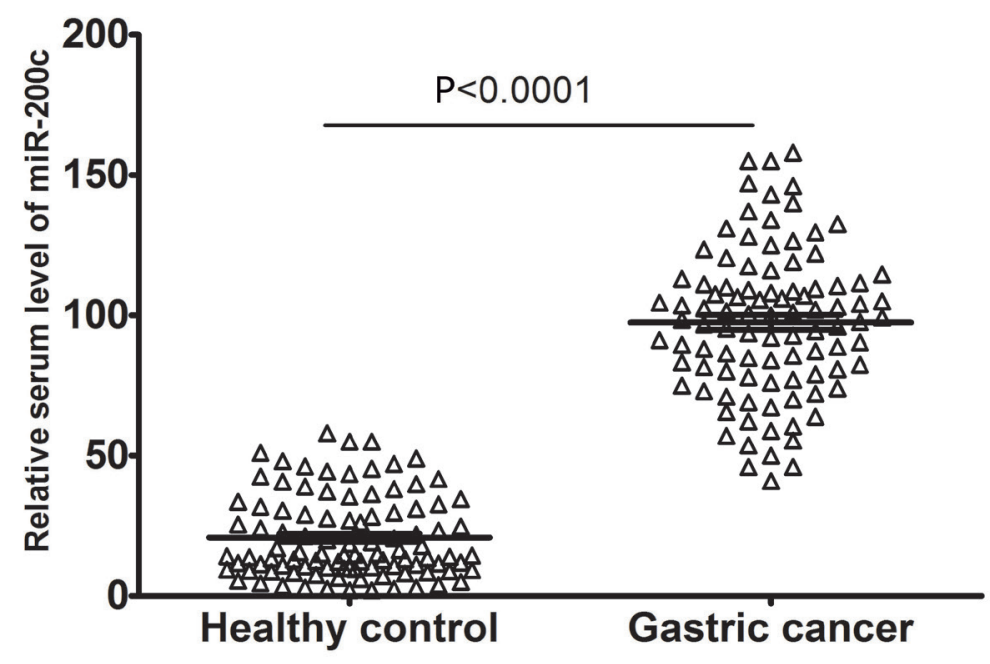

Figure 1. Relative expression level of miR-200c in blood samples. 


\section{Correlation between miR-200c and clinicopathological features of GC}

To better understand the potential roles of serum miR-200c in GC development and progression, the correlation between the serum miR-200c levels and the clinicopathological factors of the GC patients were also assessed. The Mann-Whitney test showed that there was no marked correlation between the miR -200c levels and factors such as age $(P=0.53)$, gender $(P=0.66)$, histological type $(P=0.11)$, tumor size $(P=0.09)$, lymph node metastasis $(P=0.06)$ and surgery type $(P=0.07)$ (Table 1$)$. However, serum miR-200c level was significantly associated with tumor grade $(P=0.01)$, and TNM stage $(P=0.009)$ (Table 1).

\section{Correlation between serum expression of miR-200c and survival time of GC patients}

Kaplan-Meier survival curves demonstrated that OS was significantly lower in the patients with high serum miR-200c level than in those with low levels (27.9 vs 55.9\%, P = 0.007; Figure. 2). As shown in Table 2, multivariate analysis confirmed that the HR of death was significantly higher in patients with high serum miR-200c expression levels compared with low expression levels $(\mathrm{HR}=$ $4.01,95 \% \mathrm{Cl}=2.67-10.02, \mathrm{P}=0.006)$. In addition, the higher TNM stage $(P=0.01)$ and higher tumor grade $(P=0.009$ ) were also significantly associated with elevated HR of death for $G C$ patients.



Figure 2. Kaplan-Meier analysis of 5-year overall survival in $98 \mathrm{GC}$ patients in relation to serum miR-200c expression level. 
Table 2. Multivariate analyses for prognostic factors in patients with GC.

\begin{tabular}{llll}
\hline Variables & HR & $95 \% \mathrm{Cl}$ & $\mathrm{P}$ value \\
\hline Age & 1.33 & $0.37-2.01$ & 0.31 \\
Gender & 1.02 & $0.28-3.87$ & 0.66 \\
Histological type & 1.38 & $0.36-4.41$ & 0.29 \\
TNM stage & 3.89 & $2.11-8.18$ & 0.01 \\
Lymph node involvement & 3.12 & $0.89-7.19$ & 0.06 \\
Tumor size & 2.19 & $0.76-6.11$ & 0.11 \\
Tumor grade & 4.12 & $2.89-9.63$ & 0.009 \\
Surgery type & 1.76 & $0.67-4.16$ & 0.17 \\
Serum miR-200c level & 4.01 & $2.67-10.02$ & 0.006 \\
\hline
\end{tabular}

\section{DISCUSSION}

Gastroscopic screening for GC is currently the most reliable screening tool, but it is unsuitable as a first-line examination due to its invasive nature. There is a need for discovering some noninvasive biomarkers to improve the detection of GC. RNA from apoptotic or necrotic tumor cells and circulating tumor cells after lysis can be released to the circulating blood in various forms (Thery et al., 2002), but the RNA molecules in body fluids have limited biomarker applications due to generally lower circulating levels. Studies have found that circulating miRNA in serum and plasma is usually stably bound to proteins and not in free form (Chen et al., 2008), thus resistant to RNase degradation (Arroyo et al., 2011). Therefore, circulating RNA may be a potential biomarker in cancer diagnosis and prognosis (Deddens et al., 2013).

miR-200c is a member of the miR-200 family, which was previously shown to inhibit epithelialto-mesenchymal transition (EMT) by targeting the transcriptional repressor of cadherin 1(CDH1), zinc finger E-box binding homeobox 1 (ZEB1), and survival of motor neuron protein interacting protein 1(SIP1); this suggests that these miRNAs could prevent tumor progression by negatively regulating ZEB transcriptional repressors and consequently maintaining E-cadherin junctions and preventing EMT (Bracken et al., 2008; Gregory et al., 2008; Korpal et al., 2008; Park et al., 2008). Upregulation of miR-200c had been found in several cancers, including ovarian cancer (lorio et al., 2007; Bendoraite et al., 2010), cervical cancer (Lee et al., 2008), bile duct cancer (Meng et al., 2006), nasopharyngeal carcinoma (Zhang et al., 2010), lung cancer (Liu et al., 2012), and colorectal cancer (Zhang et al., 2013; Cristobal et al., 2014), as well as GC (Tang et al., 2013; Song et al., 2014).

Previously, Valladares-Ayerbes et al. (2012) found that miR-200c blood expression in GC patients was upregulated and that it had the potential to be a predictor of progression and survival. They showed that the miR-200c blood expression levels in GC patients were significantly higher than in normal controls $(P=0.018)$. The AUC-ROC was $0.715(P=0.012)$. Sensitivity, specificity and accuracy rates of $65.4,100$ and 73.1 , respectively, were observed. There was a correlation $(P=0.016)$ with the number of lymph node metastases and the increased expression levels of miR-200c in blood were significantly associated with a poor OS (median OS, 9 vs 24 months; $\mathrm{P}=$ 0.016 ) and progression-free survival (PFS) (median PFS, 4 vs 11 months; $P=0.044$ ). Multivariate analyses confirmed that the upregulation of miR-200c in the blood was associated with OS (HR $=2.24 ; \mathrm{P}=0.028)$ and PFS $(\mathrm{HR}=2.27 ; \mathrm{P}=0.028)$, independent of clinical covariates. However, until now, the serum expression level of miR-200c and its clinical significance in GC among Asian population had not been investigated.

In the present study, we determined circulating miR-200c expression by qRT-PCR. We found that the relative serum miR-200c level was significantly higher in patients with GC than 
healthy controls. The serum miR-200c level was significantly associated with tumor grade and TNM stage. Kaplan-Meier survival curves demonstrated that OS was significantly lower in patients with high serum miR-200c level than in those with low levels (27.9 vs 55.9\%, P = 0.007). In addition, multivariate analysis confirmed that HR of death was significantly higher in patients with high serum miR-200c expression levels compared with low expression levels $(\mathrm{HR}=4.01,95 \% \mathrm{Cl}=2.67-10.02$, $\mathrm{P}=0.006$ ). Empirically, HR of more than 1.5 is considered to be a strong prognostic factor (Hayes et al., 2001), so miR-200c could be considered a potent prognostic biomarker for GC.

In conclusion, our study provided a potential biomarker for evaluation of surgery outcomes of GC in Asians. By combining serum miR-200c expression level with conventional clinicopathological factors, we may be able to predict GC outcome more accurately, leading to additional therapeutic intervention. More in-depth and larger scale studies are required to confirm the correlation described here.

\section{REFERENCES}

Arroyo JD, Chevillet JR, Kroh EM, Ruf IK, et al. (2011). Argonaute2 complexes carry a population of circulating microRNAs independent of vesicles in human plasma. Proc. Natl. Acad Sci. U. S. A. 108: 5003-5008.

Bendoraite A, Knouf EC, Garg KS, Parkin RK, et al. (2010). Regulation of miR-200 family microRNAs and ZEB transcription factors in ovarian cancer: evidence supporting a mesothelial-to-epithelial transition. Gynecol. Oncol. 116: 117-125.

Bertuccio P, Chatenoud L, Levi F, Praud D, et al. (2009). Recent patterns in gastric cancer: a global overview. Int. J. Cancer 125: 666-673.

Bracken CP, Gregory PA, Kolesnikoff N, Bert AG, et al. (2008). A double-negative feedback loop between ZEB1-SIP1 and the microRNA-200 family regulates epithelial-mesenchymal transition. Cancer Res. 68: 7846-7854.

Chen X, Ba Y, Ma L, Cai X, et al. (2008). Characterization of microRNAs in serum: a novel class of biomarkers for diagnosis of cancer and other diseases. Cell Res. 18: 997-1006.

Cortez MA and Calin GA (2009). MicroRNA identification in plasma and serum: a new tool to diagnose and monitor diseases. Exp. Opin. Biol. Ther. 9: 703-711.

Cortez MA, Welsh JW and Calin GA (2012). Circulating microRNAs as noninvasive biomarkers in breast cancer. Recent Res. Cancer Res. 195: 151-161.

Cristóbal I, Rincón R, Manso R, Caramés C, et al. (2014). Deregulation of miR-200b, miR-200c and miR-429 indicates its potential relevant role in patients with colorectal cancer liver metastasis. J. Surg. Oncol. 110: 484-485

Deddens JC, Colijn JM, Oerlemans MI, Pasterkamp G, et al. (2013). Circulating microRNAs as novel biomarkers for the early diagnosis of acute coronary syndrome. J. Cardiovasc. Transl. Res. 6: 884-898.

Esteller M (2011). Non-coding RNAs in human disease. Nat. Rev. Genet. 12: 861-874.

Ferro A, Peleteiro B, Malvezzi M, Bosetti C, et al. (2014). Worldwide trends in gastric cancer mortality (1980-2011), with predictions to 2015, and incidence by subtype. Eur. J. Cancer 50: 1330-1344.

Gregory PA, Bert AG, Paterson EL, Barry SC, et al. (2008). The miR-200 family and miR-205 regulate epithelial to mesenchymal transition by targeting ZEB1 and SIP1. Nat. Cell Biol. 10: 593-601.

Hayes DF, Isaacs C and Stearns V (2001). Prognostic factors in breast cancer: current and new predictors of metastasis. J. Mamm. Gland Biol. Neoplasia 6: 375-392.

Iorio MV, Visone R, Di Leva G, Donati V, et al. (2007). MicroRNA signatures in human ovarian cancer. Cancer Res. 67: 86998707.

Kong YW, Ferland-McCollough D, Jackson TJ and Bushell M (2012). microRNAs in cancer management. Lancet Oncol. 13: e249-e258.

Korpal M, Lee ES, Hu G and Kang Y (2008). The miR-200 family inhibits epithelial-mesenchymal transition and cancer cell migration by direct targeting of E-cadherin transcriptional repressors ZEB1 and ZEB2. J. Biol. Chem. 283: 14910-1494.

Lee JW, Choi CH, Choi JJ, Park YA, et al. (2008). Altered MicroRNA expression in cervical carcinomas. Clin. Cancer Res. 14: 2535-2542.

Liu XG, Zhu WY, Huang YY, Ma LN, et al. (2012). High expression of serum miR-21 and tumor miR-200c associated with poor prognosis in patients with lung cancer. Med. Oncol. 29: 618-626.

Meng F, Henson R, Lang M, Wehbe H, et al. (2006). Involvement of human micro-RNA in growth and response to chemotherapy in human cholangiocarcinoma cell lines. Gastroenterology 130: 2113-2129. 
Park SM, Gaur AB, Lengyel E and Peter ME (2008). The miR-200 family determines the epithelial phenotype of cancer cells by targeting the E-cadherin repressors ZEB1 and ZEB2. Genes Dev. 22: 894-907.

Rutnam ZJ and Yang BB (2012). The involvement of microRNAs in malignant transformation. Histol. Histopathol. 27: 1263-1270.

Song F, Yang D, Liu B, Guo Y, et al. (2014). Integrated microRNA network analyses identify a poor-prognosis subtype of gastric cancer characterized by the miR-200 family. Clin. Cancer Res. 20: 878-889.

Tang H, Deng M, Tang Y, Xie X, et al. (2013). miR-200b and miR-200c as prognostic factors and mediators of gastric cancer cell progression. Clin. Cancer Res. 19: 5602-5612.

Thery C, Zitvogel L and Amigorena S (2002). Exosomes: composition, biogenesis and function. Nat. Rev. Immunol. 2: 569-579.

Valladares-Ayerbes M, Reboredo M, Medina-Villaamil V, Iglesias-Díaz P, et al. (2012). Circulating miR-200c as a diagnostic and prognostic biomarker for gastric cancer. J. Transl. Med. 10: 186.

Yang L (2006). Incidence and mortality of gastric cancer in China. World J. Gastroenterol. 12: 17-20.

Zhang GJ, Zhou T, Liu ZL, Tian HP, et al. (2013). Plasma miR-200c and miR-18a as potential biomarkers for the detection of colorectal carcinoma. Mol. Clin. Oncol. 1: 3793-3784.

Zhang L, Deng T, Li X, Liu H, et al. (2010). microRNA-141 is involved in a nasopharyngeal carcinoma-related genes network. Carcinogenesis 31: 559-566. 